EVS28

KINTEX, Korea, May 3-6, 2015

\title{
Unraveling User Type Characteristics: Towards a Taxonomy for Charging Infrastructure
}

\author{
J. Helmus MSc. R. van den Hoed MSc PhD, \\ University of Applied Science Amsterdam, Weesperzijde 190, 1097 DZ Amsterdam,r.van.den.hoed@hva.nl, \\ www.hva.nl/urban-technology
}

\begin{abstract}
Many European cities with air quality concerns struggle how to further roll out charging infrastructure in the coming years in a cost effective manner. Typical concerns include charging point under-capacity (scarcity of charging points due to high demand) as well as over-capacity (placement of charging points in less prevalent locations). Being able to predict future utilization of charging stations would provide a great deal to policy makers in order to achieve more optimized infrastructure planning and roll out. This paper argues that in order to make solid predictions on the future use of charging stations one needs to acknowledge significant differences in charging behavior amongst user types, be it residents, commuters, city visitors or users of electric car sharing schemes. This paper sets out to unravel the particular charging patterns of different user types in terms of timing, charging amount and location preferences. By combining the specific user patterns with probabilities on which locations these users are likely to charge, the user-based charging patterns provide a powerful starting point to make predictions how charging points are likely to be used, as well as provide policy makers tools to make strategic decisions how to optimize the roll out of new charging infrastructure.
\end{abstract}

Keywords: EV (electric vehicle), charging behavior, infrastructure planning,

\section{Introduction}

A large number of cities have developed extensive charging infrastructure to facilitate the development for electric mobility. Several European e-mobility-related projects show how cities have moved from small scale demonstration projects, to more mature and city-covering charging infrastructure [1] [2] [3].

Many European cities with air quality concerns struggle how to further roll out charging infrastructure in the coming years in a cost effective manner [4]. Where the focus of municipalities has mainly been on the roll out of infrastructure, in most cases they lack the knowledge what determines whether the charging infrastructure used effectively or not.

Typical concerns include under-capacity (scarcity of charging points due to high demand) as well as overcapacity (placement of charging points in less prevalent locations). Both sides of concerns relate to individual charging point effectiveness and efficiency.

Although optimization of a total charging infrastructure has been investigated in earlier studies such as [5], the single charging point performance has not been operationalized on existing charging infrastructure.

Charging behavior of EV users has been subject of several studies $[5,6,7]$ that describe user power demand, start time patterns, duration and frequency of fleet users and home users. Other 
studies [8] [5] describe external factors influencing charging behavior such as weather conditions and interaction between EV users. From these studies it appeared that bad weather has a negative impact on the amount of $\mathrm{kWh}$ charged and interaction between EV users has a positive impact on EV adoption and therewith amount of $\mathrm{kWh}$ charged.

Most studies have a strong focus on energy demand implications of upscaling the EV user base. And most studies gather data varying from test projects containing 10 to 50 EV's during a test period [9] [7]. However, little is known about charging behavior in real world situations, particularly in existing charging infrastructure.

This study takes a first step in describing charging behavior in such a way that it enables to define a relation between charging point performance and charging behavior based on real world data in a metropolitan area. Contrary to other studies it contains both an EV user base of typical EV users such as home users and fleet users, as well as distinctive user groups such as taxis, car sharing and entrepreneurs. The area of subject is Amsterdam, which is frontrunner in charging infrastructure roll out [10] and implementation of new electric modalities such as large scale taxi and car sharing $[11,12]$.

The aim of this research is to provide local policy makers and charging infrastructure providers with insight in the relation of user behavior and charging infrastructure performance in order to develop an efficient rollout strategy. The results of this study can be used to predict charging infrastructure efficiency and effectiveness and thereby this paper contributes to insight and forecasting power for policy makers on how and where to further roll out new charging stations, as well as establishing success factors for more attractive business cases for charging points.

This paper takes the first step in building a research framework that connects EV user charging behavior to charging point performance. In this first step charging behavior of different types of EV users are operationalized in distinctive variables. Next, it defines hypotheses to fill in the framework. And at last it displays some first results to evaluate a number of hypotheses concerning charge behavior of particular user types.

\section{Related works}

This chapter explores available literature on charging behavior of EV users and charging infrastructure performance.

\subsection{Studies on charging behavior}

Charging behavior and charging infrastructure roll out optimization have been subject to studies since the introduction of $\mathrm{EV}$ charging infrastructure.

On the one hand there are studies that describe charging behavior results of real world EV users in pilot tests [7] [13] or semi controlled [14] [15] environments. In those studies charging behavior is operationalized in charging times and patterns derived from charge data. Some studies include driving patterns as well. Next, there are social studies on charging behavior based on enquiries or interviews for example, on range sufficiency [16]. Most studies have an observing and describing character, rather than finding out the causes of or particular characteristics of charging behavior.

Due to the current state of EV adoption and lack of large scale roll out of EV infrastructure, there is a limited amount of studies that include a wide area of scope with a high EV user density. The research on Dutch EV users' charging behavior in [17] is an exception by analyzing all mid-sized municipalities in the Netherlands. Yet, this study does not include high density EV infrastructure areas such as the Amsterdam region.

On the other hand top-down simulation and modeling studies for a to-be-rolled-out infrastructure were performed taking into account possible charging strategies of EV users [18] [19]. Those studies mainly focus at minimizing charging costs, optimal load balancing, optimal power balancing, achieving satisfactory state of energy levels [20] [21] [22]. Charging infrastructure efficiency is thus operationalized from the perspective of energy grid operators. Worth mentioning is that most top down simulations typically focus on fast charging infrastructure, while most municipalities roll out single or three phase slow charging infrastructure.

Concluding it can be said that there is a gap in literature regarding large scale analysis of charging behavior based on real world data from non-pilot situations.

\subsection{Influencing factors of charging behavior}

This paragraph develops a definition of charging behavior suitable for this research by building on related definitions found in literature. It discusses the state of the art on influencing factors on charging behavior and thereafter identifies the most relevant factors. It provides limitations and 
implications of the developed working definition as well.

Charging behavior can be seen as the resultant of a decision made by the EV user to charge a car after driving in which the user has a certain degree of freedom in choosing time of charging, location of charging and duration of charging.

The degrees of freedom within this decision strongly depend on the individual situation of the EV user, for example an almost empty full electric vehicle (FEV) has less degrees of freedom than a PHEV car user.

EV users interact in a socio-technical system containing charging infrastructure elements (charging points), a fleet of electric vehicles, and formal rules such as local policy and unwritten rules in these interactions such as etiquettes [8].

Many studies have developed either an integrated or specific model for charging behavior with driver related, vehicle related and infrastructure related dimensions; [16] [17] [5], see Table 1 for examples. Based on those studies charging behavior thus is the result of three types of interacting influencing factors: factors related to the driver, to the infrastructure and to the vehicle.

Table 1: Influencing factors on charging behavior [17]

\begin{tabular}{|l|l|}
\hline Driver related & $\begin{array}{l}\text { EV Experience, degree of trip } \\
\text { and charging planning, social } \\
\text { interaction }\end{array}$ \\
\hline Infrastructure related & $\begin{array}{l}\text { Charging point area, Charging } \\
\text { point density, parking } \\
\text { pressure, ratio of types of } \\
\text { charging points, infrastructure } \\
\text { policy }\end{array}$ \\
\hline Vehicle related & $\begin{array}{l}\text { Vehicle type, Battery size, } \\
\text { range, consumption }\end{array}$ \\
\hline
\end{tabular}

Driver related charging behavior starts when EV users have the intention to charge their car. In literature several different points of view are mentioned regarding the intention and rationality of charging behavior. On the one hand some researchers define (re)charging strategies that EV users deliberately tend to exhibit [18] [23]. Those strategies vary from overnight charging to short parking charging. The degree of trip and charging planning is high for such users.

On the other hand other researchers tend to focus on the bounded rationality and relation between user experience and charging behavior [8] [5]. For example the often mentioned range anxiety influences the charging behavior [16], yet this is also a resultant of the amount of experience a specific EV user has. One could thus argue that charging behavior develops from an unsteady state of charging behavior to a more steady, consistent behavior as users gain more experience with $\mathrm{EV}$ charging.

A related question is whether driving patterns should be part of charging behavior as well. One could argue that if the transition between driving and charging takes place at the moment that the intention of a EV driver to charge turns into the decision of charging, that from that moment the last driven miles should be seen as charging. This is when the intention to charge takes over the function of driving. The length of the path in time and space are part of the charging behavior and could be used in cluster analysis to distinguish specific user groups. For example the groups of users that carefully plan charging or the users that decide to charge as soon as they see a free charging spot. If charging behavior is seen as intentional behavior, then insight in last mile decisions could help to optimize EV infrastructure use.

A reason to include driving patterns in EV charging behavior is that some researches [24] support the concept of central optimization of EV charging infrastructure load balancing by routing EV users to specific charging points. This would result in imposed last mile driving patterns contrary to the intentional patterns.

The last aspect of driver related charging behavior is that EV users interact with each other influencing timing and location of charging. Illustrative is the phenomenon where EV users use social media services to influence charge behavior, for instance that one EV user with a fully charged car makes space for another user to charge its car [8]. A result of this social interaction is that the charge intention and moment of start charging will differ.

The second category of influencing factors of charge behavior is infrastructure-related. Speidel and Braun (2014) [25] emphasize the interaction between charging infrastructure and the user. According to their research, the geographic area (or neighborhood) that forms the context of a particular charging station determines the effect of the EV infrastructure on the EV user. For example charging stations in shopping areas result in different behavior than charging stations in low parking pressure environments.

Jabeen et al. [9] state that users explicitly choose to charge at work or at public charging points due to parking pressure yet inexplicitly choose to charge at home. 
Speidel and Braunl [25] suggest driving patterns within the infrastructure, charging characteristics, charge timing, and vehicle penetration are the key factors behind EV energy usage. Driving patterns could be of particular interest in areas that have EV infrastructures being rolled out. In low and increasing density infrastructure, the driving pattern from an occupied to free charging point could help stakeholders to efficiently further roll out the infrastructure. In very dense infrastructure such as Amsterdam south region this pattern might not be that relevant since the trip from one station to the other too short to measure effects.

However, the combination of parking pressure, charging demand and charging point density may explain particular charging behavior such as parking behavior at charging points and the use of other than preferred charging stations. Particularly in dense charging infrastructure areas where charging demand exceeds the supply of charging points EV users could encounter occupied chosen charging stations, leading EV users to use other than their preferred charging station.

The local policy regarding parking at charging points plays a role in charging behavior as well. On the one hand, the local policy in Amsterdam states that the two parking spots next to a charging stations are only allowed for EVs connected to that charging station. Note that this policy states connected not charged. The policy thus prohibits non-EV cars to charge at one of the two parking places next to a charging spot, whereas non charging yet connected EVs are allowed to park at this spot. In theory EV users can decide to park their EV connected but not charging on a free EV parking spot in a high parking pressure area. Speidel and Braunl [25]found $~ 90 \%$ parking time in their Australian trial. On the other hand, in Berlin the local policy explicitly states charging, not connecting. Berlin is known to remove fully charged electric vehicles even at night. This implies that a for a given local policy separation between parking intentions and charging intentions should be made when studying charging behavior.

Vehicle properties are the third external factor that influences charging behavior as mentioned in literature. The type of EV such as PHEV (plug in hybrid electric vehicle) or FEV (full electric vehicle) has a large impact on some of the dimensions of charging behavior such as frequency and charging amount in terms of kilowatt-hours. Yet, other EV user preferences such as arrival times would probably not been affected by the type of $\mathrm{EV}$.

\subsection{Definition of charging behavior}

Now that different aspects of charging behavior are discussed a specific definition of charging behavior is defined in this paper in order to be able to evaluate developed hypotheses against the available data in the dataset for this study. In this study charging behavior is defined as a successful result of the intentional behavior to charge a specific EV at a preferred charging point. The intention for charging is affected by the factors defined in Table 1. In this definition the successful result refers at the charge session generating measurable parameters initiated after searching for and driving to a charging station. As a result of this definition the unsuccessful charge sessions, thus situations in which $\mathrm{EV}$ users have an intention to charge, yet no charging point in the vicinity are not taken into account in this study.

\section{Methodology}

This paper is focused on distinguishing different user types and developing relevant parameters in able to measure charging behavior. This was done by extracting available parameters from literature, complemented by parameters found in discussions with key stakeholders in the supply chain of charging infrastructure. A framework was set up for measuring user charging behavior, including a selection of the parameters expected to be suitable for measuring charging behavior.

Next, a set of different user types was developed based on discussions with policy makers from the municipality of Amsterdam, a leading city in the Netherlands when it comes to developing charging infrastructure. For each user type assumptions were made regarding the distinctive user behavior. The assumed behavior was then transformed into measurable user characteristics and collected in the developed framework. For a first evaluation of the developed framework a dataset of charging sessions in the city of Amsterdam was used to validate whether these user types can be found in the data. Finally, the implications and possibilities of applying these user types for optimizing the rollout of charging infrastructure were shortly discussed.

\subsection{Data collection}

For the first evaluation of the developed framework the data collected in two large databases provided by the charging point operators responsible for rolling out 1000 charging points by 2014 and made available by the municipality of 
Amsterdam (as data-owner) was used. At the end of 2014 more than 1125 charging points were exploited. In 2014 more than 380,000 charge sessions were logged of more than 10.000 charge cards. This provides a unique dataset that allows to establish deeper insight in actual usage of charging points and distinguish between different user types as well as test the hypotheses concerning the expected charging behavior. The raw data delivered by the charging point operators first needed to be prepared before becoming of use in this research. A more precise description of the data preparation and filtering of this study is described in [26].

\section{Results: Framework for user types}

In order to develop a framework for user types literature was to identify relevant parameters in 4.1 before developing assumptions on expected user charging behavior in 4.2.

\subsection{Measurable parameters of charging behavior}

A growing amount of papers related to charging infrastructure use parameters for characterizing charging station types and user groups. Most papers distinguish one or two types of users (home and work charging), while more detailed charging behavior is likely to occur within these two broad category. Given that the dataset in Amsterdam includes a user base of more than 5000 users it is relevant to establish whether indeed different user types can be discerned. Therefore, more distinctive characteristics are needed to prevent overlapping of user types.

Most studies [5, 18, 6, 16] operationalize charging behavior in terms of charge $\mathrm{kWh}$, weekly charge time pattern, parking time ratio (defined as the noncharging time over the total connection time), weekly and hourly energy supply pattern, weekly driving patterns. Those are relevant measures taken into account in this study as well. Yet, while those measureable properties of charging behavior are relevant, they do not reflect the consistency of the behavior of users, e.g. while some users may be fairly consistent in charging behavior (likely commuters) others may have a more diverse charge pattern (for instance users of electric or visitors).

Therefore in addition, this study includes consistency per user type as well by taking into account the standard deviation of several parameters, such as start and end time and $\mathrm{kWh}$. It also takes into account the mean amount of charging point used per charging sessions. This is referred at as charging point volatility for a given charging infrastructure density per transaction per user type.

Another parameter that is assumed to be distinctive for user types in this study is the time ratio (TR), defined as the ratio between connection time and charging time. In a typical situation an EV user might be connected for 8 hours at a charging location of which 4 hours or charging takes places. This results in a TR of $50 \%$.

Furthermore, the parameter charging point volatility measures the strength of the user preference for specific charging points. Some types (e.g. residents or commuters) of users may charge at only a few charging points whereas others might use many charging points (car sharing, visitors). There is a difference in the absolute and relative volatility, since the available amount of charging points per user per charge session is not constant. For instance, the car sharing scheme may use all charging points in Amsterdam anytime and everywhere, whereas the residents are bounded to the parking zone that they have access to. Moreover, the density of charging points within a parking zone, thus available to a specific EV user, differs per parking zone and is unstable over time since the rollout of EV infrastructure is a continuous process. Therefore, the relative charging point volatility takes into account the available charging points for a specific EV user for each single moment that a transaction takes place.

In addition to aforementioned studies, this study explicitly takes into account several stereotypes of EV users and therewith takes into account the shape of the relative distribution of connection time per hour of the day over the total amount of charge sessions per user.

Another addition of this study is the time between sessions for a specific user (TBS or $\lambda$ ), defined as the time between two charge sessions (see Figure $1)$.

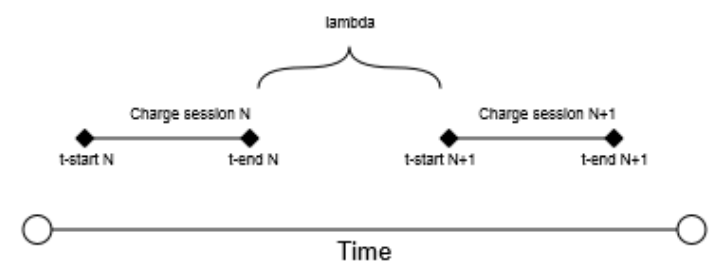

Figure 1: definition of lambda

This TBS and the standard deviation of the TBS per user and user type could be used as an indicator 
of which user type a specific EV user is. For example a large and irregular TBS could indicate at typical visitor. Furthermore, using TBS allows to develop correlations with other parameters. For example, in the dataset of this study the driving patterns are unknown; yet, the strength of correlation between lambda and charged $\mathrm{kWh}$ $(\mathrm{C}, \mathrm{L}, \mathrm{kWh})$ could provide an indication the driving pattern of an EV user.

A correlation that is assumed to be distinctive for several user types, is the correlation between the start time of a session and the time ratio of that session (C,S,TR). A strong correlation indicates that the time that a user starts charging highly affects the time ratio of that charge session. For example, residents are assumed to leave from home around a standard time, yet could have arrived the previous day at different times. If for instance the amount of kWh charged and therewith the charging time is constant, then arriving later at home will lead to higher time ratio. This might not be the case for car sharing scheme users.

The pattern type displays the relative distribution of connection hours per hour of the day (0 to 23). The pattern type is generated by transposing the start and end time of each charge session to a distribution table that sums the amount of time of that session per hour of the day. For instance a session that starts at 9:30 $\mathrm{AM}$ and ends at 11:45 AM results in three rows in the transposed table (1) hour number 9 with $50 \%$, (2) hour number 10 with $100 \%$ and (3) hour number 11 with $75 \%$ fill. Summing up all the percentages results in the charge pattern visible in Figure 5. The pattern graphs are generated by summing up all transposed connection hours per charge sessions per hour of the day divided by the total amount of connection hours per user over all time.

Table 2 gives a non-mathematical overview of the parameters used in this study. Most parameters are researched in this study as mean per user to indicate the impact of the charging behavior and standard deviation to research the consistency of the user behavior.

Table 2: parameters of charging behaviour

\begin{tabular}{|l|l|}
\hline Sign & Explanation \\
\hline Start time & $\begin{array}{l}\text { Mean and standard deviation of the start time } \\
\text { of first charge session of the pattern. This is } \\
\text { measured at the left side of the pattern, see } \\
\text { Figure 5. }\end{array}$ \\
\hline End time & $\begin{array}{l}\text { Mean and standard deviation of the end time } \\
\text { of last charge session of the pattern. This is }\end{array}$ \\
\hline
\end{tabular}

\begin{tabular}{|c|c|}
\hline & $\begin{array}{l}\text { measured at the right side of the pattern see } \\
\text { Figure } 5 \text {. }\end{array}$ \\
\hline Duration & $\begin{array}{l}\text { Mean and standard deviation of the } \\
\text { connection time. }\end{array}$ \\
\hline $\mathbf{T B S}_{\text {weekdays }}$ & $\begin{array}{l}\text { Mean and standard deviation of time between } \\
\text { two charge sessions during weekdays. }\end{array}$ \\
\hline $\mathbf{T B S}_{\text {weekends }}$ & $\begin{array}{l}\text { Mean and standard deviation of time between } \\
\text { two charge sessions during weekdays. }\end{array}$ \\
\hline kWh & $\begin{array}{l}\text { Two types of parameters are taken into } \\
\text { account. The mean and deviation of the kWh } \\
\text { charged; and the mean and standard deviation } \\
\text { of } \mathrm{kWh} \text { charged divided by largest charge } \\
\text { session over all charge sessions. The latter } \\
\text { discounts the effect of the car type. }\end{array}$ \\
\hline $\begin{array}{l}\text { Charging } \\
\text { point } \\
\text { volatility }\end{array}$ & $\begin{array}{l}\text { Variability of amount of charging points per } \\
\text { charge session corrected by available } \\
\text { charging points per session. This parameter is } \\
\text { used both absolute as well as relative. } \\
\text { Absolute is the mean amount of charging } \\
\text { points user per charge session. Relative takes } \\
\text { into account the relevant available charging } \\
\text { points per session for the specific EV user. }\end{array}$ \\
\hline Time Ratio & $\begin{array}{l}\text { Mean and standard deviation of the charging } \\
\text { time divided by connection time }\end{array}$ \\
\hline C,L,kWh & $\begin{array}{l}\text { Correlation between the time between two } \\
\text { charge sessions and the amount of charged } \\
\mathrm{kWh} \text { of the last session. For this parameter } 0 \\
\text { is no correlation and } 1 \text { is maximum } \\
\text { correlation. }\end{array}$ \\
\hline C,S,TR & $\begin{array}{l}\text { Correlation between time ratio and start time } \\
\text { of last session. For this parameter } 0 \text { is no } \\
\text { correlation and } 1 \text { is maximum correlation. }\end{array}$ \\
\hline Pattern type & $\begin{array}{l}\text { Type of pattern as displayed in example } \\
\text { figures. The pattern is formed by the } \\
\text { percentage of total of connection hours per } \\
\text { hour of the day }\end{array}$ \\
\hline
\end{tabular}

\subsection{Assumptions on user charging behavior}

It is known that within the Amsterdam area several user types are present. These are residents, commuters, car sharing scheme users, taxis, visitors and entrepreneurs. The car sharing program and electric taxi companies have an exclusive contract with the municipality of Amsterdam. In this contract the exclusive right to provide their services is agreed with the delivery of the charge card numbers of the vehicles to the municipality in return. In this study when mentioning car sharing as a user, the charge card of one car that could be used by all car sharing users is referred at since the car sharing program members could use all cars and the individual car sharing member information is not known. Although entrepreneurs are a new and growing part of the EV population, they are currently left out of this study since not enough data was present in the dataset. 


\subsubsection{Residents}

Residents are expected to have a strong weekly pattern of end-charging in the morning and startcharging in the evening at weekdays and no fixed pattern charging behavior in the weekend. Typically no correlation is expected between the start connection time and end connection time. A weak correlation is expected between the start charging time and the time ratio. Furthermore some residents might display a medium to strong correlation between the amount of charged energy and the time between two charge sessions. Over time a typical valley pattern is expected to be visible in connection time per hour.

\subsubsection{Commuters}

Like residents, commuters are expected to have a clear pattern on weekdays. Commuters tend to leave on the same day as they arrive. They tend to start charging in the morning and depart (disconnect) in the afternoon on weekdays. Like residents, an irregular pattern of charging is expected to be displayed in weekends. Little to no correlation is expected between the amount of charged energy and the time between two charge sessions. Over time there is a typical hill pattern visible in connection time per hour.

\subsubsection{Taxis}

Taxi drivers are expected to charge at home between shifts of work, at taxi business location during working times and at any location for short periods during shifts. This implies a threefold charging behavior that is regular over weeks. The taxi business location is not public infrastructure and therefore not part of charging behavior in this research. The connection times are expected to be significantly shorter than residents and commuters and the time ratio tends to appear higher than residents and commuters. A medium to strong correlation between start connection time and end connection time is expected. The difference between weekdays and weekends is less visible than the other users, since taxi drivers have a seven days' workweek .

\subsubsection{Visitors}

Visors are expected to display irregular pattern of arrival, tend to charge more often in weekends than weekdays and tend to start connecting in the morning and end in the evening. Like commuters, they are expected to limitedly charge overnight. The variety of time ratio is expected to be high due to the differences in behavior between the visitors.
Also, they are expected to charge on public charging spaces in high parking pressure areas more than low parking pressure areas.

\subsubsection{Car sharing}

There are many car sharing users using one single car. In this research the charge card of each single car is focused on, which implies the sum of all users of the car. Car sharing users are expected to start connecting all day at various charging points all over the city, except for late at night. Next, car sharing cars are assumed to drive during traffic peak times and thus not charging at traffic peak times. Therefore, in the hourly charging pattern dips are expected during traffic peak times. The car sharing cars tend to be disconnected before being fully charged except at night, therefore the time ratio generally is high. There is a difference between weekdays and weekends, since traffic peak times in weekends tend to be different than during weekdays. This might be visible in hourly patterns, amount of charge sessions and daily amount of kWh charged.

\subsubsection{RC chargers}

A small part of the residents tend to charge as commuters as well. In those cases a double charging behavior pattern containing elements from both commuters as well as residents can be seen.

\subsection{Charging behavior parameters}

The assumed behavior of the different user types from the previous paragraph were operationalized in measureable charging behavior parameters, summarized in Table 3. Based on the assumptions it was possible to fill in all parameters with sufficient details to distinguish user types. Note that the values in Table 3 are expected values to be validated against the dataset.

The pattern type displays the relative distribution of connection hours per hour of the day (0 to 23), see paragraph 4.1. It can be seen that only when the pattern type is hill type (see Figure 5), the mean start and mean end times are meaningful. The reason for this is that in a multiple saw teeth pattern the various mean start times (e.g. 9:00 AM and 6:00 PM) will result in 1:30 PM, which is not meaningful since no session starts at that time. Therefore in case of other patterns, the spread of the start and end times were given.

It can also be seen that some parameters, particularly the ones indicating a correlation, tend 
to vary within certain degrees per individual user. Yet, it is assumed that the variance on these parameters between users outside the user typology is larger than the variance within the user typology.

The absolute $k W h$ charged appears not to be a meaningful parameter for charging behavior since it reflects the different car type in the user types that contain multiple car types BEV, PHEV. This causes an unnecessary high standard deviation of the $\mathrm{kWh}$. Therefore the relative parameters were described in Table 3.

However, the Taxis in this research are all Tesla model $\mathrm{S}$ and the car sharing cars are all Smart fortwo's . For those user groups both the absolute as well as the relative parameters are meaningful to use.

When looking closer at the residents and commuters it can be seen that at weekdays the commuters and residents are assumed to be practically inverse to each other. Yet, at weekends there is a difference. Residents are assumed to charge more in weekends, whereas commuters may make occasional visits during weekends.

The C,L,kWh parameter is assumed to be high only for the car sharing cars. This parameter could be seen as an indicator of the degree of solely using public charging infrastructure (and not private). The RC chargers might also solely use public charging infrastructure and therefore are assumed to have a higher $\mathrm{C}, \mathrm{L}, \mathrm{kWh}$ as well. 
Table 3: Charging behaviour parameters

\begin{tabular}{|c|c|c|c|c|c|c|}
\hline Sign & Residents & Commuters & Taxis & Visitors & Car sharing & RC chargers \\
\hline Start time & $\begin{array}{l}\text { Weekdays } \\
\text { between 5:00 } \\
\text { PM and 7:00 PM } \\
\text { with low } \\
\text { standard } \\
\text { deviation } \\
\end{array}$ & $\begin{array}{l}\text { Weekdays } \\
\text { between 7:30 } \\
\text { AM and 9:00 } \\
\text { AM with low to } \\
\text { medium standard } \\
\text { deviation } \\
\end{array}$ & $\begin{array}{l}\text { Varies, at night, } \\
\text { around midday at } \\
\text { residential zones, } \\
\text { spread over the } \\
\text { day in other } \\
\text { zones }\end{array}$ & $\begin{array}{l}\text { Mostly between } \\
\text { 10:00 AM and } \\
\text { 2:00 PM, high } \\
\text { standard } \\
\text { deviation }\end{array}$ & $\begin{array}{l}\text { All day, standard } \\
\text { deviation } \\
\text { irrelevant }\end{array}$ & $\begin{array}{l}\text { Both resident } \\
\text { and commuter } \\
\text { times }\end{array}$ \\
\hline End time & $\begin{array}{l}\text { Next morning } \\
\text { between 7:00 } \\
\text { AM and 9:00 } \\
\text { AM hours with } \\
\text { low standard } \\
\text { deviation }\end{array}$ & $\begin{array}{l}\text { Same day around } \\
6 \text { PM with low } \\
\text { standard } \\
\text { deviation }\end{array}$ & $\begin{array}{l}\text { Varies, in the } \\
\text { early morning, }\end{array}$ & $\begin{array}{l}\text { Mostly between } \\
\text { 6:00 PM and } \\
\text { 22:00 PM, high } \\
\text { standard } \\
\text { deviation }\end{array}$ & $\begin{array}{l}\text { All day, standard } \\
\text { deviation } \\
\text { irrelevant }\end{array}$ & $\begin{array}{l}\text { Both resident } \\
\text { and commuter } \\
\text { times }\end{array}$ \\
\hline Duration & $\begin{array}{l}\text { Long, around } 8 \\
\text { hours with low } \\
\text { standard } \\
\text { deviation }\end{array}$ & $\begin{array}{l}\text { Long, around } 8 \\
\text { hours with low } \\
\text { standard } \\
\text { deviation }\end{array}$ & Short, 4 hours & Long, 8 hours & $\begin{array}{l}\text { Very short } \\
\text { (around } 4 \text { hours), } \\
\text { except for } \\
\text { charging sessions } \\
\text { starting at night }\end{array}$ & $\begin{array}{l}\text { Both resident } \\
\text { and commuter } \\
\text { aspects }\end{array}$ \\
\hline $\mathbf{T B S}_{\text {weekdays }}$ & $\begin{array}{l}\text { Medium around } \\
10 \text { hours, } \\
\text { consistent per } \\
\text { user with low } \\
\text { standard } \\
\text { deviation }\end{array}$ & $\begin{array}{l}\text { Medium around } \\
10 \text { hours, } \\
\text { consistent per } \\
\text { user with low } \\
\text { standard } \\
\text { deviation }\end{array}$ & $\begin{array}{l}\text { Low ( } 2 \text { to } 4 \\
\text { hours) to } \\
\text { medium (6-8 } \\
\text { hours) }\end{array}$ & $\begin{array}{l}\text { Very long } \\
\text { (varying from } \\
\text { days to weeks), } \\
\text { inconsistent, } \\
\text { high standard } \\
\text { deviation }\end{array}$ & $\begin{array}{l}\text { Very short (2-4 } \\
\text { hours) with high } \\
\text { standard } \\
\text { deviation }\end{array}$ & $\begin{array}{l}\text { Both resident } \\
\text { and commuter }\end{array}$ \\
\hline TBS $_{\text {weekends }}$ & $\begin{array}{l}\text { Medium } \\
\text { consistency per } \\
\text { user. medium } \\
\text { standard } \\
\text { deviation }\end{array}$ & $\begin{array}{l}\text { Inconsistent per } \\
\text { user. High } \\
\text { standard } \\
\text { deviation }\end{array}$ & $\begin{array}{l}\text { Low ( } 2 \text { to } 4 \\
\text { hours) to } \\
\text { medium (6-8 } \\
\text { hours) }\end{array}$ & $\begin{array}{l}\text { Very long } \\
\text { (varying from } \\
\text { days to weeks), } \\
\text { inconsistent, } \\
\text { high standard } \\
\text { deviation } \\
\end{array}$ & $\begin{array}{l}\text { Very short (2-4 } \\
\text { hours) with high } \\
\text { standard } \\
\text { deviation }\end{array}$ & $\begin{array}{l}\text { Inconsistent, } \\
\text { medium standard } \\
\text { deviation }\end{array}$ \\
\hline kWh & $\begin{array}{l}\text { Mean } 60 \% \text { of } \\
\text { max kWh of car } \\
\text { type, ,medium } \\
\text { standard } \\
\text { deviation }\end{array}$ & $\begin{array}{l}\text { Mean } 80 \% \text { of } \\
\text { max kWh of car } \\
\text { type, medium } \\
\text { standard } \\
\text { deviation }\end{array}$ & $\begin{array}{l}\text { Inconsistent per } \\
\text { session, high } \\
\text { standard } \\
\text { deviation, many } \\
\text { times max kWh } \\
\text { of car battery }\end{array}$ & $\begin{array}{l}\text { Inconsistent per } \\
\text { user, high } \\
\text { standard } \\
\text { deviation across } \\
\text { all user types } \\
\text { even with same } \\
\text { cars }\end{array}$ & $\begin{array}{l}\text { Median around } \\
60 \% \text { of max } \\
\text { battery capacity } \\
\text { mean is slightly } \\
\text { lower. }\end{array}$ & $\begin{array}{l}\text { Consistent per } \\
\text { user, could vary } \\
\text { based on early or } \\
\text { later charging } \\
\text { session at a } \\
\text { specific day }\end{array}$ \\
\hline $\begin{array}{l}\text { Charging } \\
\text { point } \\
\text { volatility }\end{array}$ & $\begin{array}{l}\text { Mean low (1-5) } \\
\text { for absolute } \\
\text { volatility, } \\
\text { individual users } \\
\text { could deviate }\end{array}$ & $\begin{array}{l}\text { Very low (1-3) } \\
\text { absolute } \\
\text { volatility }\end{array}$ & $\begin{array}{l}\text { Medium (around } \\
\text { 10), except for } \\
\text { home charging } \\
\text { between shifts }\end{array}$ & $\begin{array}{l}\text { High over all } \\
\text { users, medium } \\
\text { (around 8) per } \\
\text { user }\end{array}$ & $\begin{array}{l}\text { High > } 80 \\
\text { charging points } \\
\text { used, absolute } \\
\text { volatility and } \\
\text { relative volatility } \\
\text { high as well } \\
\end{array}$ & $\begin{array}{l}\text { Medium (around } \\
10 \text { ) }\end{array}$ \\
\hline Time Ratio & $\begin{array}{l}\text { Low, consistent } \\
\text { around } 20-30 \%\end{array}$ & $\begin{array}{l}\text { Medium, per } \\
\text { user consistent } \\
\text { around } 20-30 \%\end{array}$ & $\begin{array}{l}\text { High on the short } \\
\text { sessions medium } \\
\text { on the longer } \\
\text { sessions (around } \\
40 \% \text { ) }\end{array}$ & $\begin{array}{l}\text { Low, } \\
\text { inconsistent } \\
\text { around 20-30\% }\end{array}$ & $\begin{array}{l}\text { high, many times } \\
100 \% \text { mean } \\
\text { around } 40 \%\end{array}$ & $\begin{array}{l}\text { Low, } \\
\text { inconsistent } \\
\text { around 20-30\% }\end{array}$ \\
\hline C,L,kWh & $\begin{array}{l}\text { Medium }(\sim 0.5) \text {, } \\
\text { varies per user }\end{array}$ & $\begin{array}{l}\text { Low to none ( } 0 \\
\text { to } 0.2) \text {, varies per } \\
\text { user }\end{array}$ & $\begin{array}{l}\text { Medium }(\sim 0.5), \\
\text { depending on } \\
\text { starting time }\end{array}$ & $\begin{array}{l}\text { Low to none, } \\
\text { varies per user }\end{array}$ & $\begin{array}{l}\text { High }(\sim 0.8) \text {, for } \\
\text { all users }\end{array}$ & $\begin{array}{l}\text { Medium to high } \\
\text { (0.5 to } 0.8 \text { ) }\end{array}$ \\
\hline C,S,TR & $\begin{array}{l}\text { High correlation } \\
\text { between, later } \\
\text { arrival tends to } \\
\text { result in higher } \\
\text { time ratio }\end{array}$ & $\begin{array}{l}\text { High correlation } \\
\text { between, later } \\
\text { arrival tends to } \\
\text { result in higher } \\
\text { time ratio }\end{array}$ & Low for all users & Low for all users & Low for all users & $\begin{array}{l}\text { Low, due to the } \\
\text { combination of } \\
\text { both patterns }\end{array}$ \\
\hline $\begin{array}{l}\text { Pattern } \\
\text { type }\end{array}$ & Valley & hill & $\begin{array}{l}\text { Multiple saw } \\
\text { teeth }\end{array}$ & $\begin{array}{l}\text { Flatt with } \\
\text { possible peaks }\end{array}$ & $\begin{array}{l}\text { Valley at } \\
\text { daytimes when } \\
\text { driving flat at } \\
\text { night }\end{array}$ & $\begin{array}{l}\text { Flat pattern with } \\
\text { two small valleys } \\
\text { for travel time }\end{array}$ \\
\hline
\end{tabular}




\section{Initial evaluation of results}

In this paragraph, a few of the measurable parameters in for known user types Table 3 are compared with the data in the dataset. The known user types are recognized by the RFID card number in the dataset. These are taxis and car sharing cars. The unknown part of the data thus contains the other groups (commuters, residents, visitors ad RC chargers). In this paragraph the pattern type, start times and $\mathrm{kWh}$ distribution and charging point volatility are illustrated.

\subsection{Pattern types}

The pattern type displays the relative distribution of connection hours per hour of the day (0 to 23). The pattern type is generated by transposing the start and end time of each charge session to a distribution table that sums the amount of time of that session per hour of the day. Figure 2 displays six pattern types found in the dataset. The $\mathrm{x}$-axis in the graphs is the hour number starting at 0 and ending at 23. The y-axis in this graph is the percentage of all charge session that include that specific hour of the day. It can be seen that the yaxis have different scales due to the different dispersions.

Figure 2 displays six typical user patterns of the relative distribution of connection hours per clock hour as found in the available databases. In this figure the saw teeth pattern of the taxi driver is clearly visible. It can be seen that this taxi driver has more short charging sessions during daytimes and more long sessions in the evening. Clearly visible for this user type is that little to no connection takes place between 5 and 11 AM. The reason for that could be that these taxis have exclusive license to transport persons to Schiphol airport and the first flights after night depart from 6 AM.

The two residents' profiles display a valley like pattern. One can see that the valley in the pattern of resident 1 starts and stops earlier than resident 2. It can be hypothesized that resident 2 has a job that starts and ends later.

The commuter in Figure 2 displays a typical hill type pattern, although the peak at $9 \mathrm{AM}$ in Figure 2 displays an unexpected high amount of charging hours at that time. The tail of the hill could indicate that this user works overtime. The tiny blocks at night indicate that this car has charged overnight few times. It could be that the user had another vehicle back home while leaving the car at the charging station at night. A clear difference between the commuter and the residents is that the value of the bottom in the residents pattern is much higher. A reason for this could be charging in the weekends.

The car sharing pattern displays the charging all day with a slight dip in the afternoon and a little peak around 12:00 PM. The reason for this could be that car sharing cars are mostly used at that time. The visitor found in the dataset displays an interesting pattern. On one hand a clear pattern of arrival in the morning and leaving in the evening is visible. On the other hand some overnight charging is visible as well. This may indicate two subtypes of charging behaviour within the visitors user type.

It can be said that the patterns found in the data show a reasonably good match with the operationalised hypotheses in Table 3. 


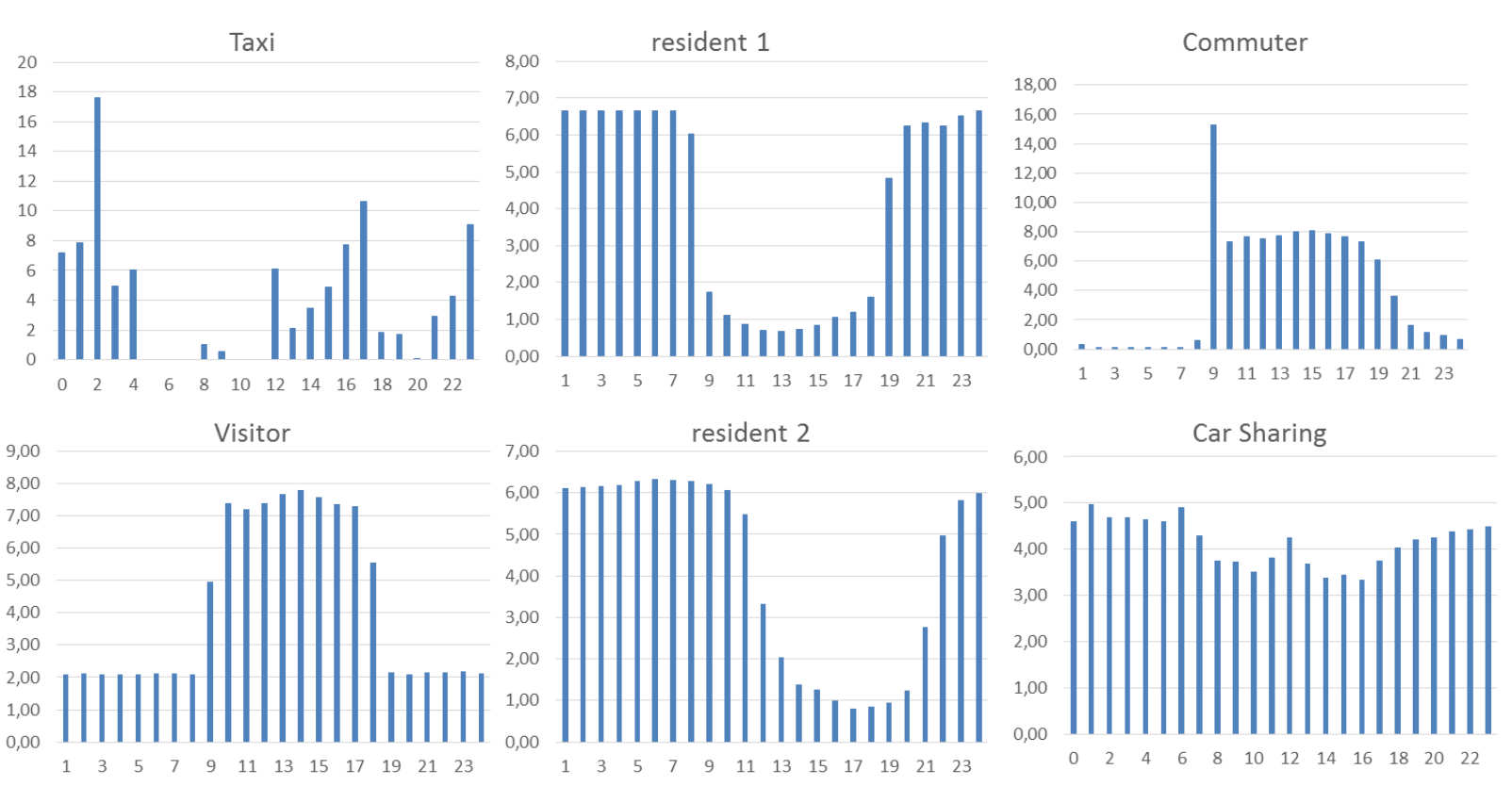

Figure 2: Six illustrations of typical connection patterns found in the dataset

\subsection{Starting times}

The Schiphol taxi drivers are known to mostly live in the Amsterdam district "Nieuw-West". Since the introduction of electric taxis the amount of $\mathrm{kWh}$ increased exponentially.

Figure 3 displays the start of charge sessions of the taxis in district Nieuw West, which is assumed to be home charging. It can be seen that many sessions of taxi drivers start at night, after the evening shift, or just for the evening around 4 PM.

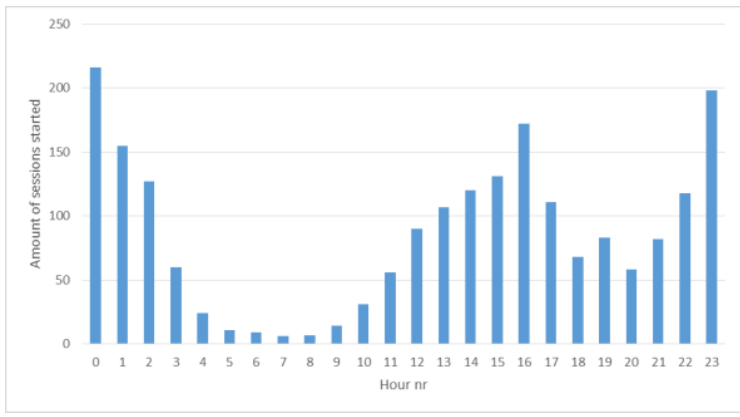

Figure 3: amount of sessions started per hour for taxis at typical home locations

Contrary to this pattern of the start of charge sessions of the taxi driver population at typical business locations follow another pattern. Figure 4 displays the amount of charge sessions of the taxi population per hour number started at business locations. The typical peaks at 12, 2PM and 4PM appear in this graph while a more dispersed distribution is visible in Figure 3.

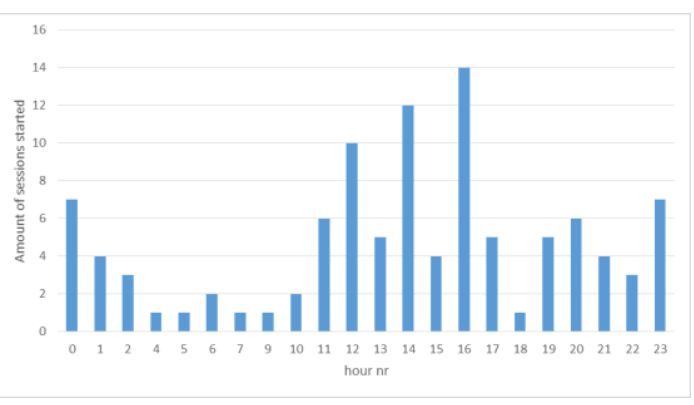

Figure 4: Amount of sessions started per hour for taxis at typical destination locations (district city Center, Westpoort, Zuid-Oost)

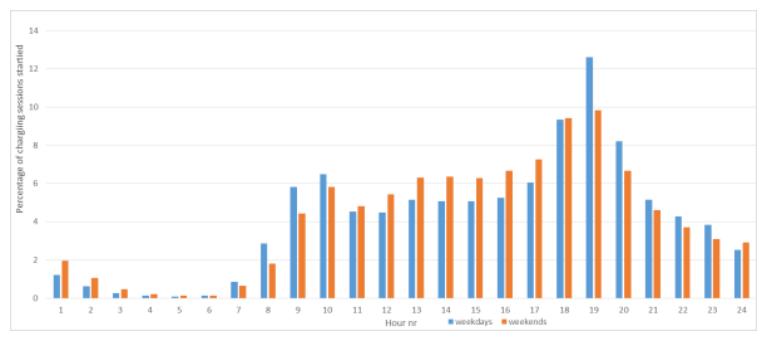

Figure 5: Distribution of start times of the unknown group (residents, visitors and commuters) in both weekdays and weekends

Figure 5 displays the relative distribution of starting times of charge sessions for commuters, residents, visitors ad $\mathrm{RC}$ chargers together for weekdays and weekends for the whole city of Amsterdam. This graphs related to the start time variable in Table 3. 
In this picture it can be seen that the peaks for starting sessions in the morning and evening are higher during weekdays than in weekends. Although the difference appears less prevalent than expected in Table 3, more insight is needed in the exact patterns of the three user groups.

In Figure 6 the distribution of start times for car sharing users is visible. The expected dip in start of charges sessions late night is clearly visible in this graph, which supports the assumed charging behavior in 4.2 .5 operationalized in Table 3 at the start time variable.

The pattern is significantly different than Figure 5, while the difference between weekdays and weekends is close to none, which also supports the parameters described in Table 3.

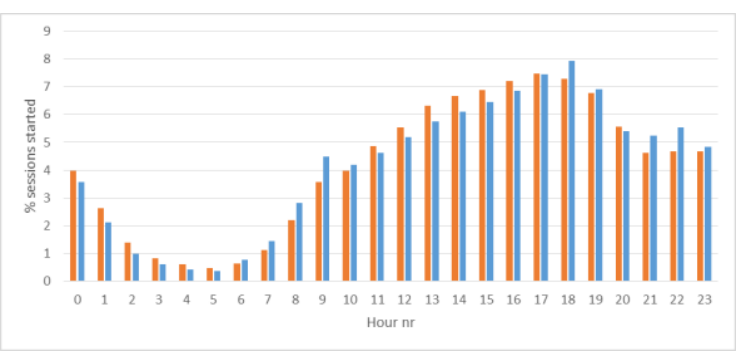

Figure 6: Distribution of start times for car sharing in both weekdays and weekends

Concluding it can be said that taxis and car sharing users support the results ofTable 3 regarding the starting times. The unknown group containing data from the residents, commuters visitors and RC chargers requires more in depth insight in specific behaviour of these user groups before support of variables in Table 3 can be claimed.

\section{3 $\mathrm{kWh}$ distribution}

In this paragraph the mean $\mathrm{kWh}$ of Table 3 charged per used group is compared with results from the dataset. Figure 7 displays the distribution of mean $\mathrm{kWh}$ charged per session for car sharing users. It can be seen that the distribution follows the normal distribution around a mean of $9 \mathrm{kWh}$ except for a few cars on the left side. The electronic Smart ForTwo's have a battery capacity of $17.6 \mathrm{kWh}$, which results in a mean of $\sim 50 \%$ full charging per session. This is in line with the operationalized assumptions in Table 3 that states that a mean of around $60 \%$ of the max battery size is charged per charge session.

1

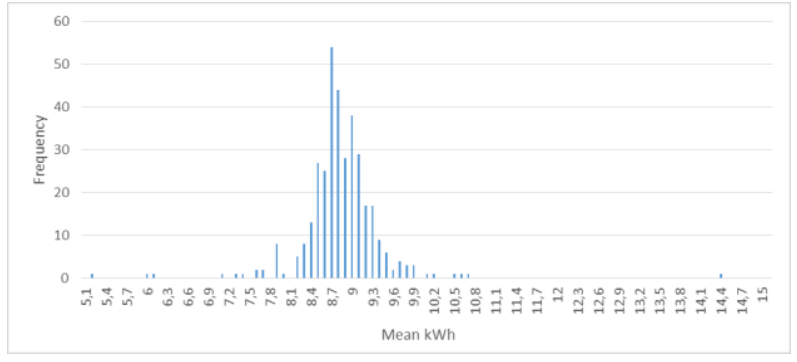

Figure 7: Frequency distribution of mean $\mathrm{kWh}$ per session for car sharing users

Figure 8 displays the frequency distribution of mean $\mathrm{kWh}$ charged per session for taxis. On the right side a normal distribution alike diagram with a mean of around $52 \mathrm{kWh}$ is visible. Next, a small amount of users displays a significantly lower mean on the left side.

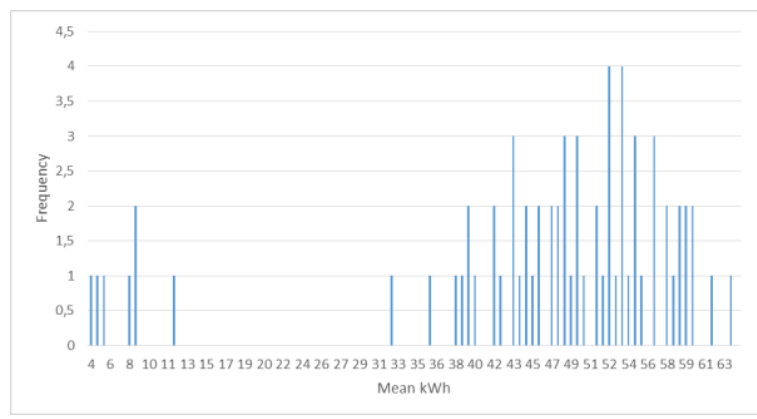

Figure 8: Frequency distribution of mean $\mathrm{kWh}$ per session for taxis

In Figure 9 the standard deviation is plotted against the mean $\mathrm{kWh}$ for three subgroups within the taxi users group. It can be seen that the group with the lower mean kWh (left side in Figure 8, lower part Figure 9) is a group with a very little amount of charge sessions. The reason for this is that the electric taxis have only been active for a few months. The group on the left side might shift towards the right side in the upcoming months as the amount of charge sessions increases.

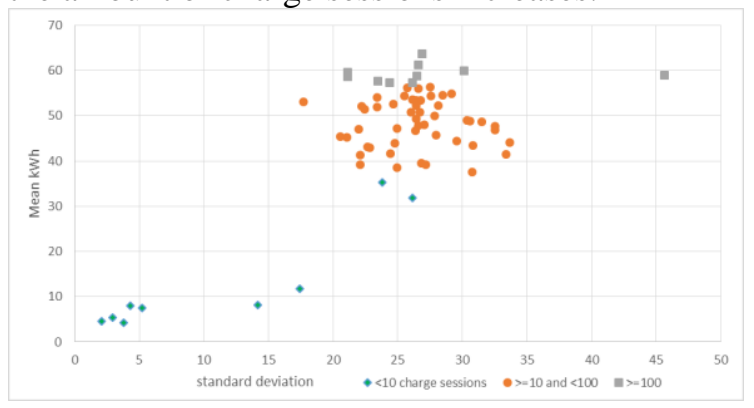

Figure 9: Mean versus standard deviation of taxis

Comparing the results of Figure 8 and Figure 9 with Table 3 it can be said that the figures support the hypotheses in the table. 
In Figure 10 and Figure 11 the left and right side of the frequency distribution of the mean $\mathrm{kWh}$ per sessions for commuters, residents, visitors ad RC chargers is displayed. The distribution is purposely cut into two diagrams since the high frequencies of the left side of the graph would diminish the right side.

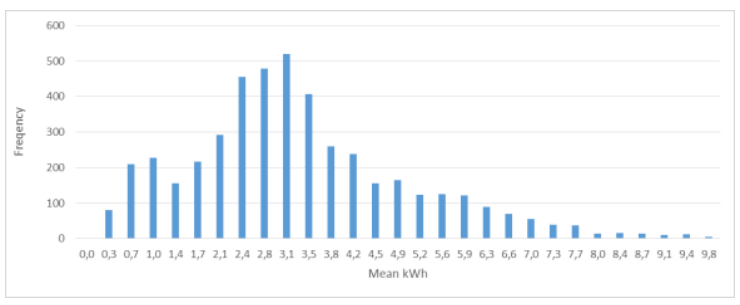

Figure 10: Mean kWh distribution for residents, visitors and commuters (left side)

It can be seen from Figure 10 that there is a large group charging a minimum amount of $\mathrm{kWh}$ per session. It would be interesting to see the exact user types and circumstances for these low $\mathrm{kWh}$ sessions in order to advise on local policy changes that improve charging point performance.

The second group on the right side of the distribution displays little coherence in the distribution. In this part of the distribution the specific EV type might play a role. More in depth research is needed to pinpoint specific mean relative or absolute $\mathrm{kWh}$ numbers to commuters, residents, visitors ad $\mathrm{RC}$ chargers group.

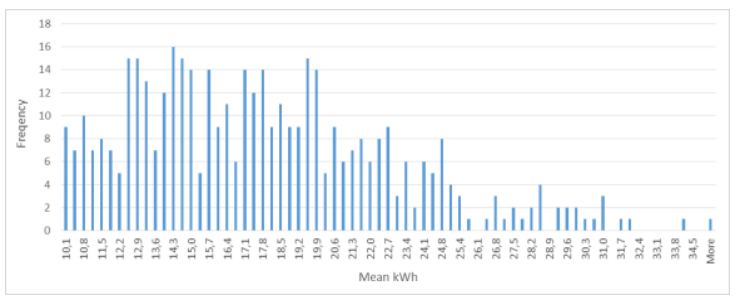

Figure 11: Mean kWh distribution for residents, visitors and commuters (right side)

\subsection{Charging point volatility}

The next three figures display the amount of charging points used versus the amount of charge sessions. The absolute charging point volatility is the quotient of those parameters. Each dot in Figure 12, Figure 13 and Figure 14 represents a single user.

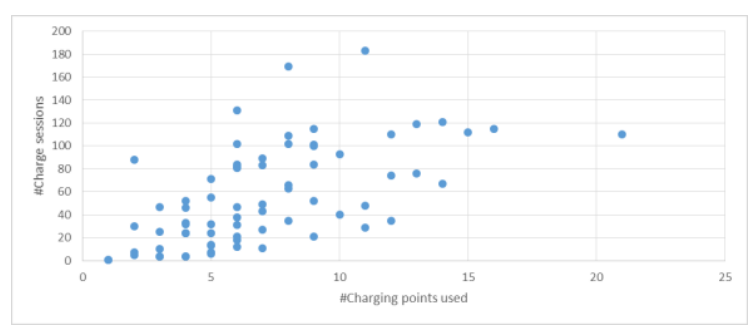

Figure 12: Absolute charging point volatility for taxis

In Figure 12 the absolute charging point volatility for taxis is visible. The mean charging point volatility of the whole user group is 8 , with a standard deviation of 6.7. Is can be seen that there is a slide correlation between the amount of charge session and the amount of charging points used.

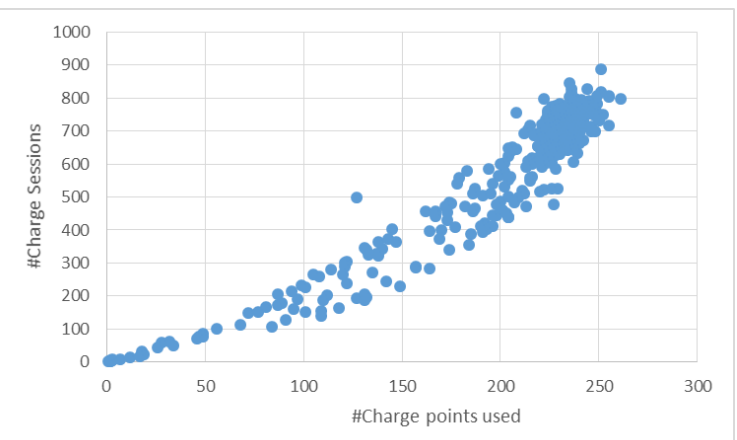

Figure 13: Absolute charging point volatility for car sharing users

In Figure 13 the charging point volatility of car sharing users is displayed. It is clearly visible that the more charging sessions a single car (thus one charging card) had made, the more charging points were used. The absolute volatility is around 3 (meaning that on average every 3 new charge sessions a new charging point is used), and the amount of charging points used varies from 15 to 270. This partly corresponds with the results of Table 3.

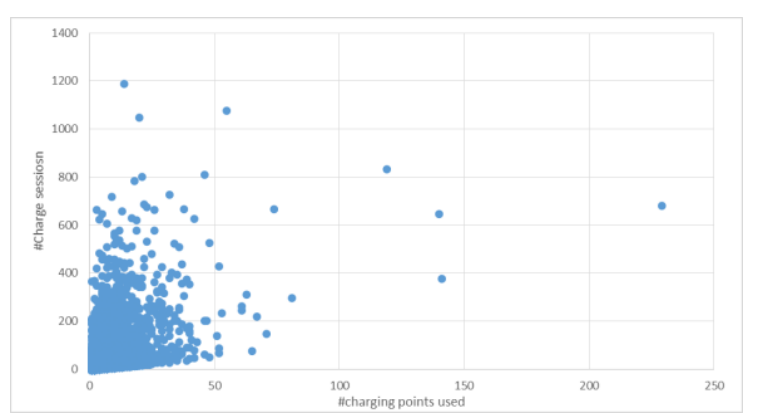

Figure 14: Absolute charging point volatility for commuters and residents 
The unknown group (commuters, residents, visitors ad $\mathrm{RC}$ chargers) displays a far more wider spread of the charging point volatility. The reason for this could be found in the fact that three user groups were displayed in a single graph. Therefore more in depth research in the differences of these user groups is needed to validate the hypotheses.

\section{Conclusion and limitations}

This paper identified a gap in literature regarding measurement of user charging behavior on large size datasets. In literature typically residents (home chargers) and commuters are identified and described by a limited amount of parameters, whereas this paper adds new specific user types.

This paper provides a number of meaningful parameters that enable to distinguish residents, commuters, visitors, taxis, car sharing users and $\mathrm{RC}$ chargers. The user types appear to differ on more than 20 parameters, which have been operationalized with expected ranges of values.

In addition to existing literature that describes parameters such as start and end times, this paper adds new parameters particularly usable in research that include wide areas of scope with a high EV infrastructure density and high EV user density. The added parameters not only describe the user behavior but also include consistency parameters per individual user and over the total user type.

Building upon the collected parameters a comprehensive framework was set up that supports in analyzing user types in large datasets. The parameters can be used for development of algorithms that monitor user EV behavior. First evaluations against a large dataset of the municipality of Amsterdam provide illustrations for the validity of the parameters but require further validation in studies that will be presented in follow-up articles. From the graphs in the first evaluation can be seen that specific user groups display significant different user behavior. Particularly the user patterns can be used to develop efficient EV infrastructure rollout strategies.

\section{Reflections for practice}

\subsection{Implications for policy makers}

The identification of distinct charging behavior among different user types at a single charging point as presented in Figure 2 provides opportunities for policy makers to optimize the occupancy and performance of these charging points. In case charging points can be placed at locations where different user types are likely to charge, combined charge patterns of user types can increase the potential occupancy significantly. Figure 15 ) displays how three types of users (car sharing, residential user and commuter) differ in charging behavior, and how on an hourly basis these charging profiles add up to a higher total occupancy without elevated peaks at peak times. Therefore, stakeholders working on roll out of EV infrastructure are likely to benefit to scan areas on user population composition to identify promising locations where charging patterns of different users may be piled up to increase user occupancy, thereby increasing the business case for the charging infrastructure..

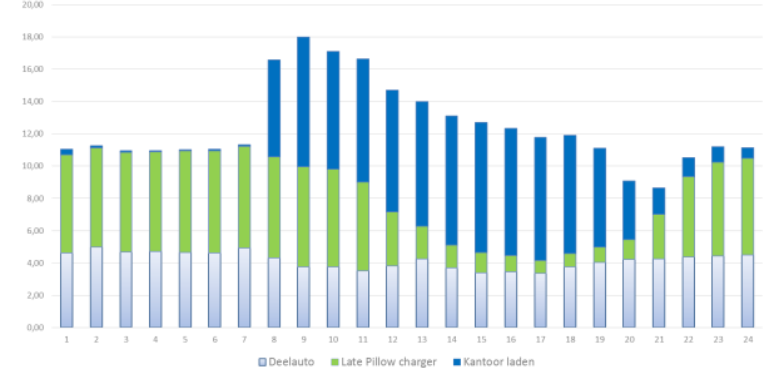

Figure 15: combination of three types of users at same charging point

\subsection{Recommendations for further research}

This research provides the first steps in developing deeper insight in measuring different user patterns based on a definition of charging behavior. A next step is to validate the defining parameters for the different user types described in table 2 as well as to identify dominant user patterns. Also other factor influencing charge patterns for particular user types will be considered such as weather conditions (identifying weather sensitivity per user type), type of EV (e.g. differences between PHEV and BEV) and EV density in relation to distance between charging points (revealing causal factor to charging point volatility). Similarly, charging behavior will be related to presence of POI's, shopping areas and parking locations (by using open data from Google Maps) to investigate area specific influences on charging behavior [27] [28]. This research will thus be conducted by adding open data to the existing database, as well as applying the database of charge sessions in the City of Amsterdam as a means of validating the user types. Next further validation in other cities will be 
carried out in order to establish a more generalized model of user types of charging infrastructure. In parallel, together with the involved municipalities, evaluation studies will be carried out whether indeed the user types can be used to optimize the occupancy of charging stations by controlled experiments.

This research is part of a larger research in which data analysis of actual charge behavior is used to support policy makers and companies in the supply chain of charging infrastructure to make more effective decisions in roll out of charging infrastructure. Apart from establishing user types, the research involves analyzing seasonal patterns, trends in charge behavior, benchmarking charge behavior between cities, and developing more predictive models that can support in optimizing the use of charging infrastructure in city boundaries. This research thereby strives to contribute to lowering the barriers for the development of charging infrastructure.

\section{Acknowledgments}

The authors would like to acknowledge policy makers of the Municipality of Amsterdam for their insights in user types as well as Gijs van der Poel from Overmorgen, Xiomara Dilrosun and Simone Maase for project support and analysis.

\section{References}

[1] MOBI Europe, „Objectives Mobi Europe,” MObi Europe, [Online]. Available: http://www.mobieurope.eu/theproject/objectives/. [Geopend 2010 2014].

[2] IEAHEV, „IA-HEV 2013 Annual Report: The Electric Drive Accelerates," IEAHEV, 2013.

[3] etecmc10, „Infrastructure Deployment,” [Online]. Available: http://etecmc10.vub.ac.be/etecphp/publicati ons/EVS18infravdb.pdf. [Geopend 2211 2014].

[4] G. Benysek en M. Jarnut, „Electric vehicle charging infrastructure in Poland.," Renewable and Sustainability Energy Reviews, vol. 16, pp. 320-328, 2012.

[5] E. Azadfar, V. Sreeram en D. Harries, „The investigation of the major factors influencing plug-in electric vehicle driving patterns and charging behaviour," Renewable and Sustainable Energy Reviews, vol. 42, p. 1065-1076, 2015 February.

[6] T. Franke en J. F. Krems, „Understanding charging behaviour of electric vehicle users," Transportation Research part F, vol. 21, pp. 75-89, 2013.

[7] Y. B. Khoo, Wang, Chi-Hsiang, P. Paevere en A. Higgins, ,Statistical modeling of Electric Vehicle electricity consumption in the Victorian EV Trial, Australia," Transportation Research Part D: Transport and Environment, p. 263-277, 2014.

[8] N. Caperello, K. S. Kurani en J. T. Hageman, „Do You Mind if I Plug-in My Car? How etiquette shapes PEV drivers' vehicle charging behavior," Transportation Research Part A: Policy and Practice, vol. 54, pp. 155-163, 2013.

[9] D. Olaru, B. Smith, B. Braunl en S. Speidel, „Electric vehicle battery charging behaviour: Findings from a driver survey," in Australian Transport Research Forum 2013 Proceedings, 2013.

[10] R. v. Hoed, J. Helmus, R. d. Vries en D. Bardok, „Data analysis on the public charge infrastructure in the city of Amsterdam," in EVS27, Barcalona, 2013.

[11] Parool, „Elektrische Tesla-taxi's rijden vanaf Schiphol door Amsterdam," Parrool, 1610 2014. [Online]. Available: http://www.parool.nl/parool/nl/30/ECONO MIE/article/detail/3770056/2014/10/16/Elek trische-Tesla-taxi-s-rijden-vanaf-Schipholdoor-Amsterdam.dhtml. [Geopend 2011 2014].

[12] Taxi-e, „Taxi-e,” 2014. [Online]. Available: http://www.taxielectric.nl/en/home. [Geopend 2011 2014].

[13] C. H, X. Jia, A. S. Chiu, H. X en X. M., „Siting public electric vehicle charging stations in Beijing using big-data informed travel patterns of the taxi fleet.," Transportation Research Part D: Transport and Environment, vol. 33, pp. 39-46, 2014.

[14] P. M., „The Environmental and Cost Impacts of the Electrification in the Azores," Massachusetts Institute of Technology, 2011.

[15] I. Bunzeck, M. Paukovic en Y. Feenstra, „User preferences for charging locations and charging schemes - a survey in eight EU 
countries," in D-Incert seminar, Amsterdam , May 20th 2014, .

[16] T. Franke en J. Krems, „What drives range preferences in electric vehicle users?," Transport policy, vol. 30, pp. 56-62, 2013.

[17] J. Spoelstra, „Charging behavior of Dutch EV drivers (Msc Thesis)," University Utrecht, Utrecht, 2014.

[18] G. M. De, P. Elena, M. Giorgio en S. Harald, „A pilot study to address the travel behaviour and the usability of electric vehicles in two Italian provinces," Case studies on Transport policy, 2014 IN PRESS.

[19] X. Xi, R. Shioshansi en V. Marano, „Simulation-optimization model for location of a public electric vehicle charging infrastructure," Transportation Research Part D: Transport and Environment, pp. 6069, 2013.

[20] J. Junga, J. Y. Chowb, R. Jayakrishnana en J. Y. Parkc, „Stochastic dynamic itinerary interception refueling location problem with queue delay for electric taxi charging stations," Transportation Research Part C: Emerging Technologies, vol. 40, p. 123-142, 2014.

[21] R. Smith, M. Morison, D. Capelle, C. Christie en D. Blair, „GPS-based optimization of plug-in hybrid electric vehicles' power demands in a cold weather city," Transportation Research Part D: Transport and Environment, vol. 16, nr. 8, pp. 614-618, 2011.

[22] M. de Gannaro, E. Paffumi, H. Scholz en G. Martini, „GIS-driven analysis of e-mobility in urban areas: An evaluation of the impact on the electric energy grid," Applied Energy, pp. 94-116, 2014.

[23] E. Paffumi, M. D. Gennaro, H. Scholz en G. Martini, „Assessment of the potential of electric vehicles and charging strategies to meet urban mobility requirements," Transportmetrica-A, p. in press, 2014.

[24] B. Sandford en J. Grønbæk, „Routing EV Users Towards an Optimal Charging Plan," in EVS26 proceedings, Los Angeles, 2006.

[25] D. Spiedel en T. Braunl, „Driving and charging patterns of electric vehicles for energy usage," renewable and sustainable energy reviews, vol. 40, pp. 97-110, 2014.

[26] R. v. d. Hoed, J. Helmus, R. d. Vries en D. Bardok, „Data analysis on the public charge infrastructure in the city of Amsterdam," in Proceedings EVS27, Barcelona, 18-20 November 2013.

[27] Amsterdam Elektrisch, „Amsterdam Elektrisch," [Online]. Available: http://www.amsterdam.nl/parkerenverkeer/amsterdam-elektrisch. [Geopend 1 12 2014].

[28] Gemeente Amsterdam, „Parkeren op straat,” [Online]. Available: http://www.amsterdam.nl/parkerenverkeer/parkeren-amsterdam/parkerenstraat/parkeren-straat/. [Geopend 2102 2015].

\section{Authors}

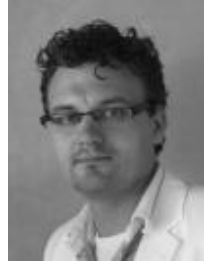

Jurjen Helmus studied Technical Business Administration at the University of Groningen (RUG) and is specialized in the field of Innovation Management.

He has worked at the University of Applied Science Amsterdam (HVA) in the Technology Management program as coordinator of the specialization Innovation Management and Business Development.

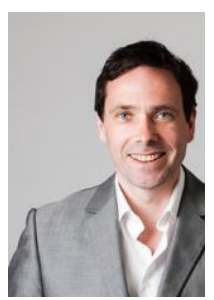

Robert van den Hoed is lector Energy and Innovation at the University of Applied Science Amsterdam (starting in 2011), and as such is one of the coordinators of the CleanTech research program. After his graduation at the faculty of Industrial Design Engineering at the Delft University of Technology he carried out his $\mathrm{PhD}$ studying how established industries react to radical technologies, with a case on hydrogen and fuel cells in the automotive industry. After finishing his $\mathrm{PhD}$ he worked at Ecofys for 7 years, a large consultancy agency in the field of sustainable energy. 